\title{
Deposition of Mucopolysaccharides in Myeloids
}

\author{
Javid Rasool, M.D., Sajad Geelani, M.D., Mohd. Shaban Wani, M.Sc.
}

Department of Clinical Haematology, Sher-i-Kashmir Institute of Medical Sciences, Soura, Srinagar

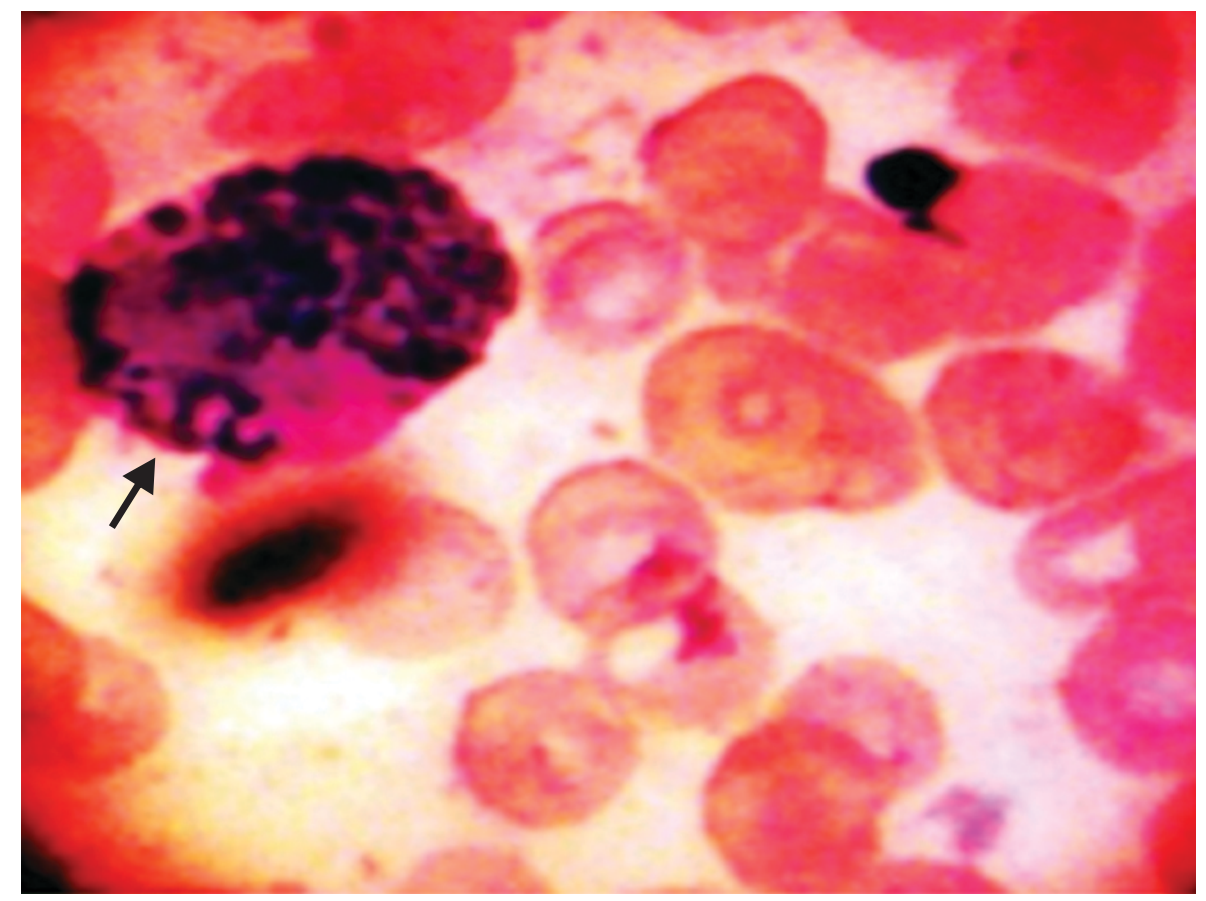

Figure showing Mucopolysaccharide deposition in Neutrophil.

Mucopolysaccharidosis (MPS) are a group of metabolic disorders caused by the absence of lysosomal enzymes needed to break down molecules called glycosaminoglycans that help to build bone, cartilage, tendon, cornea, skin and connective tissue. The material is granular and PAS positive by light microscopy. By electron microscopy it appears in the swollen lysosomes and can be identified as Mucopolysaccharides.

\section{Correspondence:}

Dr. Javid Rasool

Associate Professor

Department of Clinical Haematology,

Sher-i-Kashmir Instittute of Medical Sciences, Soura, Srinagar

E-mail: dr_javidrasool@yahoo.co.uk

Mobile : +919419080717 